\title{
LOS PORTAFOLIOS ELECTRÓNICOS COMO OPORTUNIDAD PARA EL APRENDIZAJE DE LA MULTIMODALIDAD
}

\author{
Recepción: 17/07/2016 | Revisión: 18/08/2016 | Aceptación: 14/09/2016
}

\author{
Maria del Mar SUÁREZ \\ Universitat de Barcelona \\ mmsuarez@ub.edu
}

Resumen: Ser competente en la comunicación digital en lenguas primeras y extranjeras es esencial en la era digital. Este artículo presenta la experiencia didáctica en lengua extranjera (inglés) de un proyecto transversal trilingüe (catalán, español e inglés) cuyo objetivo es promover la competencia comunicativa en entornos digitales. Más concretamente, nos centramos en la implementación del portafolio electrónico en las asignaturas de lengua de la Facultad de Educación de la Universidad de Barcelona. Los estudiantes de la asignatura de Lengua Inglesa para la Enseñanza (de entre 18 y 21 años aproximadamente) asisten a unas sesiones que versan sobre la comunicación en entornos multimodales que abarcan temas como la hipertextualidad, el uso de imágenes y los distintos tipos de tipografía, entre otros. Se espera que los estudiantes comuniquen utilizando una variedad de formatos, tales como texto, imágenes, audio y vídeo de un modo efectivo. Concluimos que el portafolio digital no solo les ayuda a adquirir competencia digital sino que también favorece la comprensión de que aprender lenguas va más allá de la mejora en las habilidades «tradicionales».

Palabras clave: portafolio digital; multimodalidad; competencia comunicativa digital; hipertextualidad.

\section{E-PORTFOLIOS AS AN OPPORTUNITYTO LEARN MULTIMODALITY}

\begin{abstract}
Digital communicative competence in first and foreign languages is key in this digital era. This pa-per presents the foreign language part of a trilingual (Catalan, Spanish and English) project the aim of which is make our students communicatively competent in digital environments. Specifically, the e-portfolio implementation for the language subjects in the Teacher Training Faculty of the University of Barcelona is analyzed. The students (18 - 21 years of age, approx.) receive training in multimodal communication, including issues such as hypertextuality, use of images and use of typography for communicative purposes, among others, in the English Language subject of their degree. They are expected to use a range of formats, such as text, image, audio and video effectively in their e-portfolio. The e-portfolio helps them to acquire digital communicative competence as well as to realize that language learning is more than mastering the four «traditional» language skills.
\end{abstract}

Keywords: e-portfolio; multimodality; digital communicative competence hypertextuality. 


\section{Introducción}

El currículum educativo español actual tiene en cuenta ocho competencias básicas, entre las cuales se encuentran el procesamiento de información y la competencia digital. Estas podrían definirse como la habilidad para buscar, obtener, procesar y comunicar información para transformarla en conocimiento. Más específicamente, consisten en buscar, seleccionar y procesar o analizar información utilizando distintas técnicas y estrategias dependiendo de la fuente y el medio en que nos hallemos (oral, impreso, audiovisual, digital o multimedia); llegar a conocer distintos tipos de información, fuentes, posibilidades, lenguaje y medios; convertir la información en conocimiento; razonar, organizar, relacionar, analizar y sintetizar información; y usar las tecnologías de la información y comunicación como herramientas con tal objetivo.

Las asignaturas de lengua son una fuente rica en oportunidades para integrar todas estas características en la planificación curricular de la materia puesto que se pueden desarrollar distintas actividades para promover no solo la integración de toda la información obtenida en la búsqueda y posteriormente analizada, sino también los distintos modos de comunicar esta información, usando la gran variedad de recursos que ofrecen las tecnologías de la información actuales. Así pues, las cuatro habilidades lingüísticas básicas (expresión oral, expresión escrita, lectura y comprensión oral) deben reinterpretarse, ya que tienen lugar en entornos de distinta índole, en contraste con lo que ocurría hasta no hace mucho. Por tanto, es necesario intervenir de modo sistemático para que todas estas nuevas habilidades reinterpretadas se adquieran con éxito, aplicándolas en estos nuevos entornos, como en el entorno de internet y, en el caso de esta experiencia didáctica, en los portafolios digitales.

Tras un sondeo inicial, en que se percibe que los estudiantes están acostumbrados a comunicarse en entornos digitales pero sin conciencia metacognitiva ni metalingüística acerca de su actividad comunicativa en esos medios, consideramos necesaria una intervención sistemática para aunar el contexto comunicativo en que tiene lugar la actividad multimodal y el tipo de habilidades y estrategias lingüísticas que se enseñan en el aula de lenguas. Esto implica la introducción de aspectos multimodales tanto en la clase de lenguas primeras como en la de lenguas extranjeras para que los estudiantes puedan comunicarse de un modo efectivo en los entornos digitales, como lo es por ejemplo, el portafolio digital, en que encontramos aunados varios modos.

Según Kress, un modo

is a socially shaped and culturally given semiotic resource for making meaning. Image, writing, layout, music, gesture, speech, moving image, soundtrack and 3D objects are examples of modes used in representation and communication (Kress, 2010:79).

Con este objetivo, debe observarse el uso de todos los elementos de modo que el estudiante pueda reflexionar y darse cuenta de las ventajas que ofrece el uso apropiado de estos recursos en comparación con el portafolio tradicional impreso. Por tanto, el rol de los profesores consiste en facilitarle al estudiante las herramientas necesarias tanto para la adquisición de la competencia comunicativa en el sentido tradicional, como las de la competencia digital en entornos multimodales. Esta nueva competencia la podríamos llamar «Competencia Comunicativa Digital» (CCD) (Pujolà et al., 2011). 
Las herramientas TIC se introducen ya en la Educación Primaria en muchas asignaturas en el sistema educativo español actual. Sin embargo, rara vez se trata la CCD explícitamente, ni en Primaria ni en Secundaria. Por otra parte, la competencia comunicativa (ya sea en sentido tradicional como en entornos digitales) se considera una competencia transversal en Educación Superior. A pesar de esto, no se trata tampoco explícitamente en ninguna asignatura a menos que se esté cursando un grado universitario en Comunicación o Lingüística, por ejemplo. Ello dificulta la plena adquisición de esta competencia al final de cualquier otro grado universitario. Ante esta situación, uno de los objetivos de esta experiencia didáctica es tratar este tema explícitamente de modo que se contribuya a la expresión y comprensión efectiva de los textos en contextos multimodales.

En la era digital, debe considerarse la comunicación de modo multidimensional, lo que permite al lector (que también es un espectador y un interlocutor en el episodio comunicativo) escoger su propio camino comunicativo. Así, interpreta los mensajes que tienen lugar en un entorno multimodal teniendo en cuenta todos los elementos que aparecen simultáneamente, más allá de la palabra, como complemento, en ese entorno digital. Esta nueva clase de lector reordena y altera su propio esquema comunicativo, es decir, interactúa con los contenidos que se le presentan (Pérez Tornero y Sanagustín Viu, 2011). En consecuencia, los propios lectores deben seleccionar y tomar sus propias decisiones al mismo tiempo que interpretan los contenidos que le aparecen en pantalla, creando así nuevos significados que puede que no aparezcan explícitos en el texto o que, incluso, el propio autor no tenía en mente al elaborarlo.

También se espera que el escritor tome en cuenta todos estos aspectos multimodales para este nuevo lector, aunque el mensaje original no sea finalmente el mismo que interprete el destinatario. Asimismo, en cualquier contexto comunicativo, el escritor tiene que tener en cuenta el tipo de destinatario al que van dirigidos sus textos para así proporcionarle las imágenes, sonidos, hipervínculos, hipermedia y cualquier otro recurso virtual que contribuya a la correcta transmisión e interpretación de su mensaje original teniendo en cuenta el tipo de audiencia al que se dirige.

Vemos, pues, que si ya de por sí no es fácil leer o escribir, estas dos tareas se tornan aún más complicadas en entornos digitales. De ahí la necesidad de prestar atención a todos los aspectos multimedia que no se encuentran en la comunicación impresa y que tienen un papel fundamental en los medios digitales. Con la introducción de estos nuevos elementos, se hace necesaria la intervención didáctica para que los estudiantes aprendan a comunicarse de un modo efectivo. Aunque a algunos profesores se los considere «inmigrantes digitales» mientras que a la mayoría de los estudiantes, y por supuesto a todos los pequeños y jóvenes se les considere «nativos digitales» (Prensky, 2001), los nativos digitales muestran carencias a la hora de comunicarse en entornos digitales por no haber recibido instrucción explícita. Del mismo modo, los profesores formados no deberían sentirse en inferioridad respecto de sus estudiantes en ese ámbito digital si nos referimos a la comunicación digital exitosa. Al contrario, aunque puede que los estudiantes tengan más destreza a la hora de comunicarse con registro informal en los espacios virtuales, especialmente en redes sociales (Tolsá, 2012), esto tampoco debe tomarse como regla sin excepción, puesto que a menudo los estudiantes muestran dificultades a la hora de comunicarse en registro y entornos formales. Por tanto, consideramos necesario tratar todos estos aspectos formalmente en la clase de lengua, ya sea de lenguas primeras o extranjeras. 


\section{Desarrollo}

Lo que sigue es un resumen de los aspectos que se tratan explícitamente en las asignaturas de lengua (catalán, español e inglés) en la Facultad de Educación de la Universidad de Barcelona. Los resultados se basan en el análisis de un grupo de 28 estudiantes de primer año de la asignatura de Lengua Extranjera para la Enseñanza (Inglés). En el estudio, de investigación-acción, se presta especial atención a la disposición del texto y al uso de imágenes, al hipermedia y al hipertexto y a las cuestiones tipográficas y de diseño. Se espera que los estudiantes apliquen estos aspectos con intención comunicativa en el portafolio que elaboran para estas asignaturas, en que muestran las evidencias de aprendizaje que han hecho durante el cuadrimestre. En el caso de la asignatura que nos ocupa, el portafolio se realiza utilizando la plataforma Mahara, de acceso libre, y consiste en tres fases principales que se representan en páginas o «vistas», que es el nombre que reciben en esta plataforma virtual en particular.

\subsection{Disposición o «layout»}

La aparición de entornos multimodales en nuestra vida cotidiana ha hecho que las imágenes y los efectos visuales hayan adoptado una posición privilegiada en cuanto a su función comunicativa. Es casi inconcebible encontrar un texto plano en un entorno digital, en que no aparezca ni rastro de color, imagen o efecto gráfico. Estas características, no obstante, no deben usarse porque sí, sino que deben tener un objetivo comunicativo. Si bien estamos acostumbrados a su presencia en los entornos digitales, no está tan claro que les prestemos la atención necesaria para interpretar su función comunicativa, aunque todos ellos tienen una, sea o no efectiva.

A pesar de la presencia global de las imágenes y efectos visuales, el estudio formal de su significado en el entorno digital no aparece explícito en los currículums. Al omitir este aspecto relevante en cualquier episodio comunicativo en formato digital en los contextos educativos formales, perdemos inexorablemente la oportunidad de familiarizarnos con los códigos y las competencias que implica el uso de la imagen. Sin embargo, creemos que enseñar el uso comunicativo eficiente de las imágenes haría que los estudiantes los utilizaran no solo como elemento decorativo sino con un objetivo comunicativo claro y crítico.

Con este objetivo, el primer paso que tomamos para mostrar cómo usar el portafolio electrónico en estas asignaturas de lengua es reflexionar sobre la posición del texto y de las imágenes en la vista así como sobre la interpretación de las mismas según su posición, significado semiótico e interacción con la producción verbal que las acompañan en esa misma «hoja» o vista.

Para ello, hacemos que los estudiantes se fijen en el número de columnas en que pueden distribuir sus evidencias de aprendizaje en cada vista. El número y anchura de estas columnas determina la distribución de estas evidencias de aprendizaje y cuánta relevancia tienen en relación con el resto de los elementos de esa vista. Por tanto, la organización de los elementos de la vista, enmarcar ciertos elementos y hacer que unos destaquen sobre los otros les proveerá de mayor o menor carga semántica (Kress y Leeuwen, 1996) y su disposición final complementará los contenidos ya presentes en las propias imágenes y textos que hayan a su alrededor. Así pues, la disposición de las imágenes y de los textos se analiza desde el punto de vista de tema y rema o, lo que es lo mismo, información nueva y ya conocida (la ya conocida a la izquierda; la nueva, a la 
derecha). Del mismo modo, se analiza la posición de los elementos más específicos en contraste con los más generales, o de la información principal en contraste con la información secundaria, como se muestra en las Figuras 1, 2 y 3.

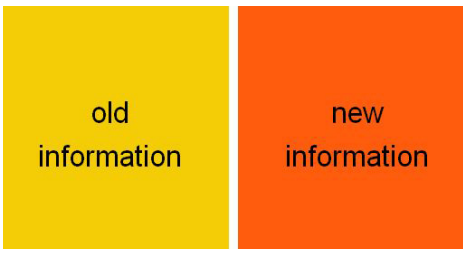

Figura 1. Información nueva y antigua.

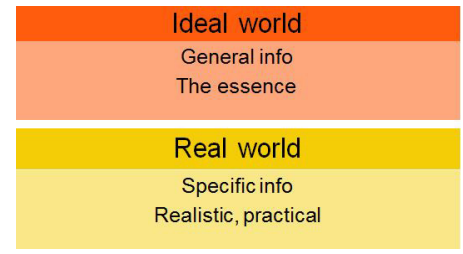

Figura 2. Información general y específica.

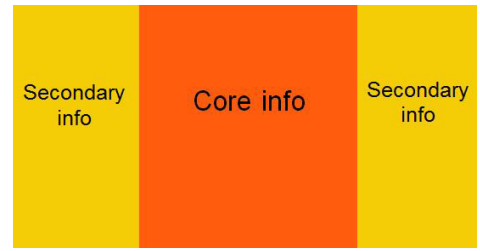

Figura 3. Información principal y secundaria.

Además, enmarcar los elementos de una vista contribuye a la creación de una clara separación y percepción de la individualidad de los mismos, mientras que las líneas que forman una continuidad, el uso de un color en distintos tonos o varios combinados consistentemente y la combinación de formas similares aportan un sentido de cohesión a los elementos de la vista (Figuras 4 y 5). No obstante, puede que algunos elementos destaquen sobre otros a pesar de mostrar un sentido cohesivo, ya sea por su tamaño o por la tonalidad en la gama de colores escogida, como se ilustra en la Figura 6.
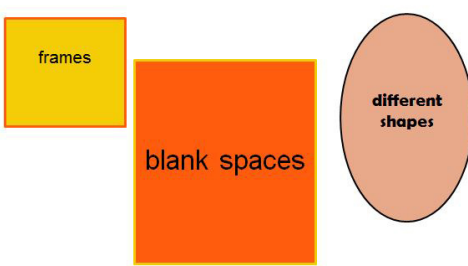

Figura 4. Desconexión entre los elementos de la vista.

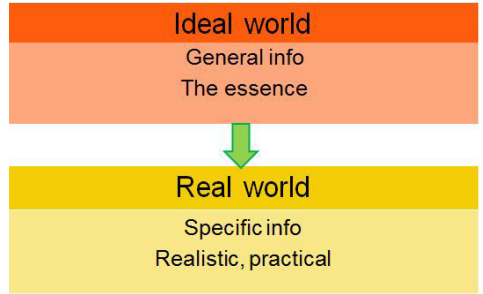

Figura 5. Conexión entre los elementos de la vista.

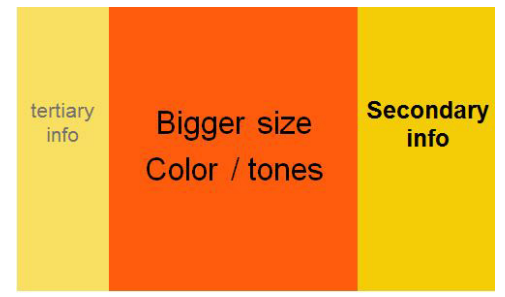

Figura 6. Prominencia dependiendo del tamaño, color y tono.

Los resultados indican que los estudiantes evitan la fragmentación excesiva. En lugar de eso, optan por una distribución uniforme de las columnas que ofrece Mahara, lo que confiere el mismo grado de importancia de los contenidos en su distribución. Otra opción muy recurrida es conferir un mayor espacio al texto, no tanto a la imagen, lo que le aporta más relevancia e indica que se las imágenes se consideran quizás como un elemento que aporta menos carga semántica o relevancia.

\subsection{Imágenes}

Partiendo del trabajo de Nöth (2001), presentamos en clase cuatro aspectos que describen la relación entre texto e imagen. Desde la perspectiva sintáctica, las imágenes se relacionan con el texto utilizando elementos como el tiempo y el espacio, es decir, su disposición física respecto del texto en la página. Semánticamente, se pueden establecer cinco relaciones distintas:

- Complementariedad: cuando se necesitan tanto el texto como la imagen para aprehender el sentido completo del contenido de la página.

- Dominancia: la relevancia de la imagen respecto del texto al que acompaña teniendo en cuenta el tipo de documento en el que aparece. 
- Redundancia: cuando el mensaje que acompaña la imagen se limita a reproducir o describir lo que ya se percibe gráficamente en la imagen.

- Discrepancia: cuando existe una desigualdad o diferencia parcial entre la imagen y el texto.

- Contradicción: cuando no se encuentra relación lógica alguna entre el texto y la imagen, ya sea intencionadamente o no.

En cuanto a las relaciones semánticas, aproximadamente el 60\% de las imágenes utilizadas por nuestros estudiantes son dominantes, aunque podríamos considerar que tienen simultáneamente una función complementaria. Sin embargo, 30\% de las imágenes eran claramente redundantes. Un ejemplo de complementariedad es la que mostramos en la Figura 7, en que la flor simboliza el proceso de aprendizaje del inglés, y como ser vivo, debe regarse para posibilitar su crecimiento. En contraste, en la Figura 8 nos encontramos con un claro ejemplo de redundancia entre la imagen y el texto, en que el título, el texto y la misma imagen se refieren al mismo concepto.

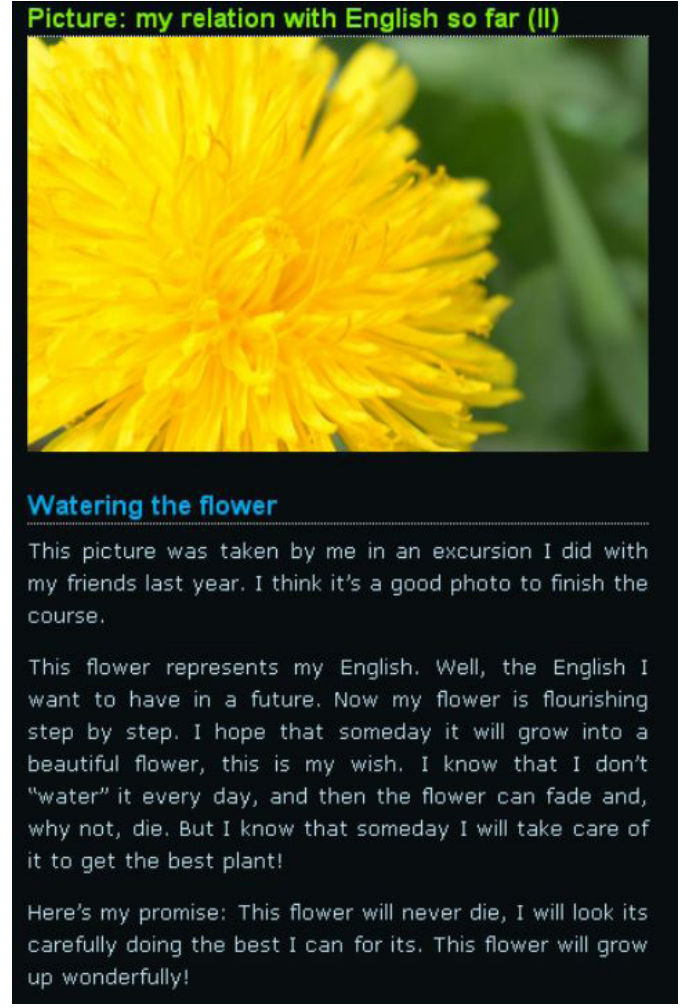

Figura 7. Imagen y texto complementarios.

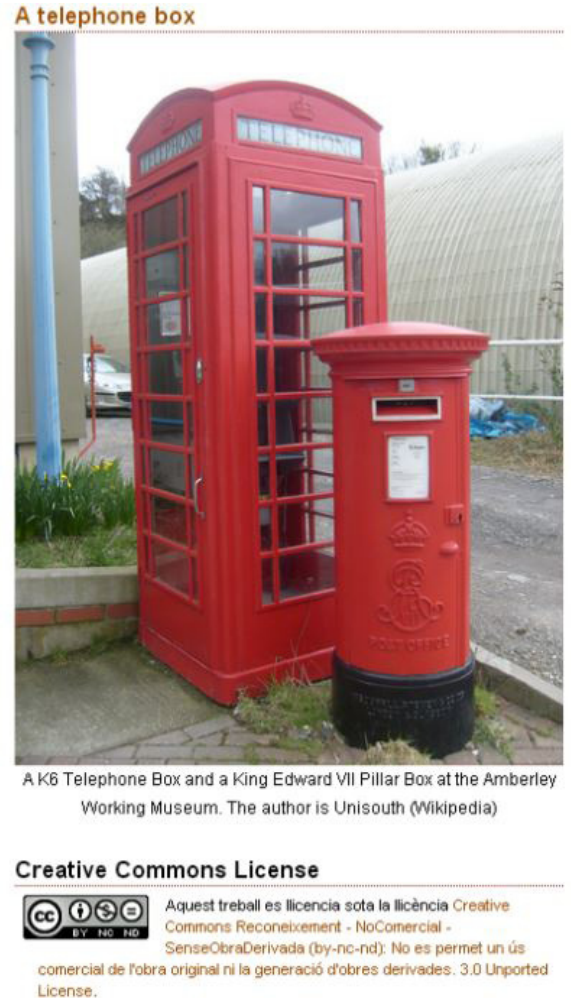

Figura 8. Imagen y texto redundantes.

Para tratar la interacción entre el lenguaje verbal y el visual, se explican en profundidad tres funciones principales (anclaje, relevo e intriga) mientras que la función de identificación solo se menciona brevemente, pues es una función con la que se supone que los estudiantes ya están familiarizados y, además, se intenta que los estudiantes profundicen en las otras. El anclaje consiste en la relación entre el texto y uno de los varios significados que puede tener una imagen dependiendo de la interpretación del que la contempla. El relevo acontece cuando la imagen no aporta toda la información que contiene el texto al que acompaña. La intriga se utiliza cuando la inter- 
pretación del mensaje en relación con el texto se sucede progresivamente. De hecho, esta es una técnica que se puede aplicar fácilmente al portafolio teniendo en cuenta su diseño y ejecución en tres fases distintas con su correspondiente retroacción tras su presentación. Esto es así porque las tres vistas tienen como uno de los objetivos el mostrar el progreso en el aprendizaje del estudiante desde el inicio hasta el fin del cuadrimestre. Sin embargo, no suele ser de las técnicas más usadas. En su lugar, los estudiantes se inclinan por el anclaje (43\%) y el relevo (50\%).

Además de la instrucción sobre el uso de imágenes con claras intenciones comunicativas, los estudiantes reciben también formación sobre cuestiones de derechos de autor y citación de imágenes, tanto propias como ajenas, siguiendo convenciones académicas. En este sentido, se presenta a los estudiantes la existencia de las licencias Creative Commons y se les provee de una lista de páginas electrónicas que contienen imágenes protegidas con este tipo de licencia.

\subsection{Hipertextualidad}

En entornos digitales, se tiende a organizar la información de forma no lineal, esto es, en una estructura interactiva multisecuencial en que el hipertexto juega un papel clave. La interacción entre el escritor y el lector de textos digitales conduce, pues, a nuevas dimensiones en la escritura y la lectura (Landow, 1995). El Marco Común Europeo de Referencia de las Lenguas (2001) trata explícitamente sobre la habilidad de saltar de un nodo a otro en un texto con hipervínculos para así poder crear un itinerario de lectura y aprendizaje propio. Existen también ya varias recomendaciones para el uso efectivo de la hipertextualidad, tales como las de Adell (1995). Gilster (1997) explica que el hipertexto ofrece muchas posibilidades de lectura y escritura de textos digitales. El escritor goza de numerosas opciones para guiar al lector a través de distintos caminos mientras que es el propio lector el que es libre de decidir qué camino tomar o en qué ruta quedarse al encontrarse un hipervínculo, puesto que los hipervínculos son en sí mismo un mecanimos para crear significado que va más allá del lugar en que aparece (Cassany, 2006). Tal variedad de posibilidades en lo que concierne a los hipervínculos abre la puerta a un mundo extremadamente rico en información, lo que puede, a su vez, llevar a un posible estado de confusión, ya sea por un exceso de información, ya sea por la irrelevancia o inadecuación de ciertos hipervínculos.

Tanto el autor como el lector de hipertextos tienen, por tanto, que esforzarse en escribir e interpretar los hipervínculos y los elementos de hipermedia de modo crítico. Es por esta razón que se tratan los siguientes puntos en el aula para el uso apropiado del hipertexto en entornos digitales. En primer lugar, debemos aclarar que usamos el término «hipertexto» para referirnos tanto a hipervínculos como a hipermedia, pues la multimodalidad de los textos en entornos digitales posibilita que tanto las imágenes como los textos se puedan hipervincular no solo a textos (en formato blog, archivo de texto o pdf o Scribd, entre otros) sino también a otros hipermedia en formato audio o vídeo (en YouTube, Vimeo, podcasts) u otros dispositivos (presentaciones en Slideshare, diccionarios en línea, etcétera).

Los aspectos más relevantes en los que se profundiza en cuanto al hipertexto son: ser capaces de seleccionar los enlaces en un texto, saber cómo limitar los hipervínculos, reconocer su función en el texto (referencial, explicativa, argumentativa o persuasiva), decidir el nodo exacto del hipertexto (ya sea interno, externo o incrustado) y acertar las expectativas del lector, guiándolo 
a la información concreta de un modo directo, sin tener que pasar por caminos que entorpezcan la lectura o que hagan que el lector se sienta perdido. Asimismo, se debe pensar también en el tipo de público para poder decidir dónde es necesario un hipervínculo para la completa comprensión del texto madre. Una de las actividades que proponemos para despertar la conciencia de los estudiantes respecto del hipertexto es debatir sobre los límites sintácticos y la utilidad de los hipertextos en textos ya publicados en la red. Para ello, proporcionamos diversos ejemplos en que algunos hipervínculos podrían considerarse inapropiados, siguiendo la presentación anterior. Algunos de los fenómenos que nos encontramos son'1:

- Excesivo: hipervincular una cláusula entera aunque probablemente un fragmento más breve hubiera bastado. En la Figura 9, por ejemplo, «recent blog post», «blog post» o simplemente «post».

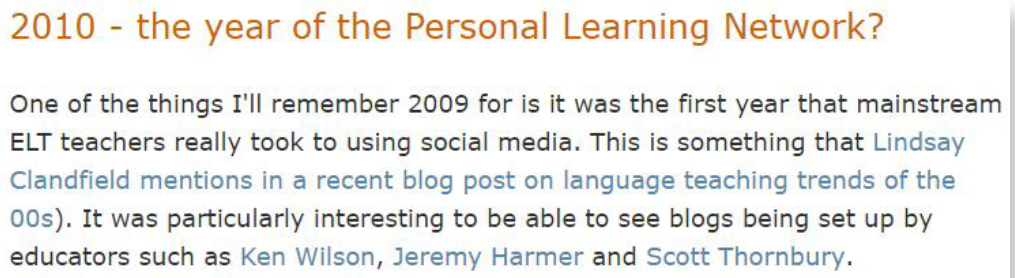

Figura 9. Recuperado el 25 de noviembre de 2016 de

http://blog-efl.blogspot.com.es/2010/01/2010-year-of-personal-learning-network.html.

- Posiblemente excesivo: en el ejemplo (Figura 10) se utilizan tanto el adverbio «here» (aquí) como «Washington Post» para referirse a la misma fuente.

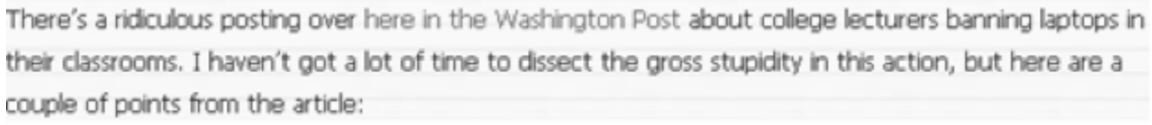

Figura 10. Recuperado el 12 de noviembre de 2014 de http://slife.dudeney.com/?p=426.

- Innecesario: el vídeo que se ha incrustado en la parte superior aparece hipervinculado más adelante con un comentario que indica su aparición anterior (Figura 11).

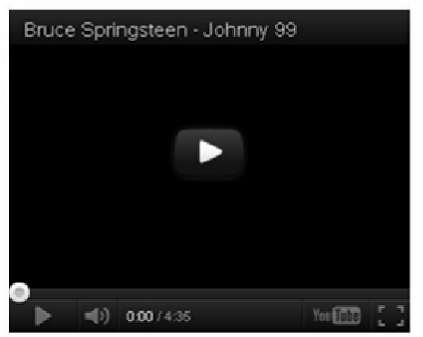

I very much liked one of the many suggestions Usoa Sol made in her talk, Listen up! Getting teens to listen in English, given at the $\mathbb{H}$ Barcelona ELT Conference getting kids to write emails from the protagonists of the song.

Usoa suggested Dido's Thank You, though I wonder if it's got a strong enough storyline and whether or not it tells us enough that we can interpret about the characters, Perhaps White Flag might work better, partly because you've got a YouTube videoclip there that appears to add something to the story.

I'm showing my age here, I guess, but one I'd really go for would be Springsteen s

Figura 11. Recuperado el 25 de noviembre de 2016 de http://www.ihes.com/bcn/tt/eltblog/blog/labels/YouTube.html.

1 Ejemplos presentados por Joan-Tomàs Pujolà en «Developing digital communicative strategies in the training of language teachers». Comunicación en TIES2012 en Barcelona, 1 de febrero de 2012. 


\subsection{Recursos tipográficos y adecuación lingüística}

Los estudiantes, tras escribir su texto, lo disponen en el entorno Mahara, combinándolo con uno de los seis temas que ofrece la plataforma. Si bien la elección inicial del color de fondo puede venir determinada por varios motivos (gusto personal, preferencia por la claridad), se convierte de todos modos en un elemento relevante cuando se debe combinar con el resto de los elementos de la vista. Esto incluye el estilo o registro utilizado o elementos más gráficos o visuales como pueden ser las imágenes, los otros colores que aparezcan en la fuente o en las imágenes y el tipo y tamaño de la fuente o fuentes escogidas, entre otros. Por tanto, el estudiante debe usar los recursos tipográficos teniendo en cuenta al menos dos aspectos: la información que proyecta o conlleva el uso de los recursos, que debería ser efectivo y directamente relacionado con la intención discursiva, y la combinación apropiada con el resto de elementos que aparezcan en la vista. Véanse, en este caso, dos ejemplos dispares. La Figura 11 podría calificar como uso erróneo de estos recursos, puesto que cada sección combina colores sin una aparente intención comunicativa. Este es de los pocos casos que se dan de uso incorrecto de los recursos tipográficos, aunque se debe constatar que los estudiantes no acostumbran a echar mano de los mismos. En la Figura 12 se han utilizado todos los recursos con esmero y con un propósito comunicativo intencionado.

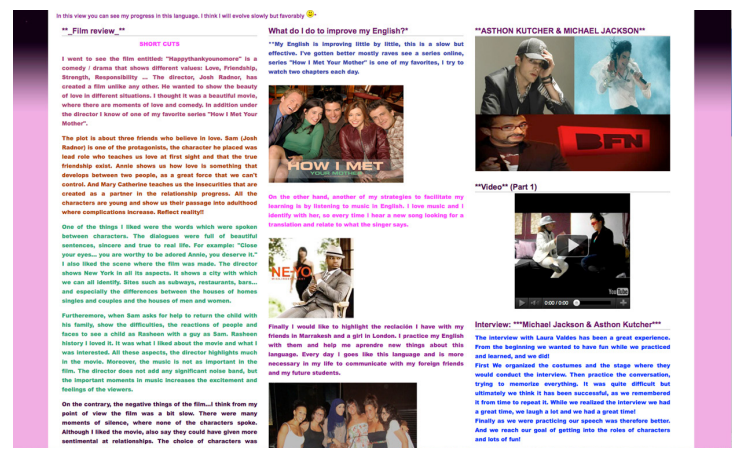

Figura 12. Uso irrelevante de los recursos tipográficos.

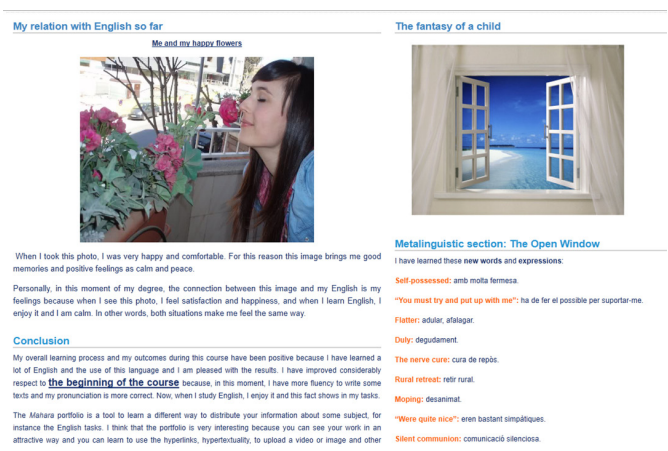

Figura 13. Uso relevante de los recursos tipográficos.

\section{Evaluación}

Aplicamos un sistema de evaluación formativa para el portafolio digital desde la primera entrega, de un total de tres. Los estudiantes reciben retroacción del profesor sobre todas las evidencias de aprendizaje aportadas y acerca de la disposición de las mismas en las vistas del portafolio digital poco después de organizar la primera y la segunda vista. Para ello, utilizamos una rúbrica de cuatro grados con cuádruple entrada. Los aspectos que incluye son:

- Multimodalidad en el portafolio digital: desde la monomodalidad hasta el uso de un discurso multimodal efectivo, incluyendo aspectos como la tipografía, los hipervínculos, el uso del color, etc.

- Estructura y equilibrio: desde la ausencia de equilibrio o estructura caótica hasta una disposición de los elementos en que se percibe una clara jerarquía de los elementos en su disposición.

- Modo verbal: se refiere tanto al grado de corrección lingüística tras la retroacción del profesor como al uso efectivo del hipertexto e hipermedia y de los recursos tipográficos. 
- Modo audiovisual: relevancia y creatividad de las imágenes así como rigor en la citación de las fuentes, incluyendo las propias.

Los entornos virtuales, a menos que requieran de una sesión de inicio, hacen posible compartir el trabajo propio casi sin límites. Aprovechando esta posibilidad, antes de que el profesor dé su retroacción sobre la tercera vista, los estudiantes escogen un par de compañeros para que les evalúen su portafolio utilizando la misma rúbrica que utiliza el profesor para las dos primeras vistas. De este modo, utilizando esa retroacción, pueden hacer los cambios que crean convenientes antes de hacer entrega de la última vista, que será evaluada por el profesor. De este modo, se promueve la reflexión metacognitiva y metalingüística de los estudiantes y se crea un ejemplo significativo y práctico de evaluación formativa.

Naturalmente, la adecuación y corrección lingüística del texto en sí son también aspectos que se tienen en cuenta para evaluar el trabajo del estudiante. Para ello, se evalúan la variedad de estructuras y vocabulario, los errores, el registro y el formato, la organización y los conectores, la cohesión, la coherencia, las faltas de ortografía y la puntuación para los textos escritos. En los ví-deos o grabaciones orales no se tienen en cuenta, obviamente, las faltas de ortografía ni la puntua-ción, pero sí la pronunciación, la fluidez y, si se trata de un diálogo, la interacción. Estos elementos se evalúan antes de su disposición en el entorno digital.

\section{Conclusión}

El uso diario de la tecnología a menudo se supone como una actividad que los estudiantes realizan de modo apropiado. Sin embargo, no siempre implica una correcta producción y recepción lingüística en entornos digitales. Si bien es cierto que el contacto constante y el uso de la lengua en dichos entornos puede desarrollar un aprendizaje incidental de las técnicas lingüísticas que se utilizan en los entornos digitales y, por tanto, pueden conducir a la adquisición exitosa de la competencia comunicativa digital, es también cierto que no todo el input que reciben los estudiantes se adecúa en los términos tratados en este artículo. Ello puede causar confusión en el usuario y potencial «prosumidor» de textos digitales (Toffler, 1980).

No podemos imaginarnos nuestra vida cotidiana sin tecnología, lo que también atañe, por extensión, al estudio de la lengua con objetivos comunicativos. Por tanto, hay una clara necesidad de proporcionar a nuestros estudiantes modelos de los cuales puedan aprender a reconocer y posteriormente usar los recursos multimodales de modo efectivo y a disponerlos de modo que el lector o visualizador del contenido multimodal pueda obtener el máximo provecho de todo aquello que esos recursos significan en todo su espectro (Kress y Leeuwen, 2001). Esto es, tener en cuenta que un texto ya no es una secuencia lineal sino que debe entenderse en relación con la imagen, el sonido y otros recursos multimodales que tenga a su alrededor. Puede que no podamos evitar la exposición de modelos un tanto cuestionables en la inmensidad que es la red, pues cualquiera puede publicar sus producciones sin apenas control. Es por ello que la instrucción formal en la clase de lengua puede ayudar a superar los efectos de ese input de calidad cuestionable y a crear lectores críticos no solo con el contenido del texto en sí sino también de lo que cualquier recurso multimodal signifique más allá de las palabras. 
Ha habido muchas propuestas que se han integrado en el currículum para poder desarrollar de un modo efectivo la adquisición de la competencia comunicativa digital. Sin embargo, creemos necesaria la ayuda institucional de modo que intervenciones de este tipo no se lleven a cabo solo en clases específicas de multimedia o tecnología, ni en asignaturas de lengua en sentido estricto, como la que nos concierne, sino que esta competencia transversal se fomente en asignaturas cuyo foco principal no es el lingüístico. La exposición constante a input de calidad y significativo conducen a la adquisición de toda competencia, sin lugar a dudas. Por tanto, creemos que la integración de la comunicación multimodal y la reflexión sobre ella debería estar presente de modo que vaya más allá de una parte de asignatura y se convierta en una actividad tan natural y sencilla como cualquier otra de nuestra vida cotidiana. Por todas estas razones, desde la Facultad de Educación, seguimos llevando a cabo investigación e innovaciones didácticas con este proyecto de portafolio digital, utilizando plataformas diversas y actualizando nuestras propuestas didácticas a la par que avanza la investigación en competencia comunicativa digital.

\section{Agradecimientos}

La autora agradece a sus compañeros de grupo de innovación docente DIDAL (antes ECAL) y del grupo de investigación REALTIC (antes DRE_DIX), en especial a Ma Ángeles García Asensio, Vicenta González, Begoña Montmany, Joan-Tomàs Pujolà y Carmen Ramos por el trabajo colaborativo referente a la multimodalidad en los portafolios y en los blogs de profesores. Esta publicación ha sido posible gracias al reconocimiento institucional de parte del proyecto 2014PID-UB/004 y al proyecto EDU 2008-05411, coordinados por Joan-Tomàs Pujolà.

\section{Referencias bibliográficas}

Adell, J. (1995). La navegación hipertextual en el World-Wide Web: implicaciones para el diseño de materiales educativos. Comunicación presentada en EDUTEC'95. Consultado el 25 de noviembre de 2016 en http://nti.uji.es/docs/nti/edutec95.html.

Cassany, D. (2006). Tras las líneas. Sobre la lectura contemporánea. Barcelona: Anagrama.

Common European Framework of Reference for Languages: Learning, Teaching, Assessment (2001). European Union Council. Consultado el 25 de noviembre de 2016 en http://www. coe.int/t/dg4/linguistic/Source/Framework_EN.pdf

Gilster, P. (1997). Digital literacy. Canada: John Wiley \& Sons Inc.

Kress, G., y van Leeuwen, T. (1996). Reading images. The grammar of visual design. London/New York: Routledge.

Kress, G., y van Leeuwen, T. (2001). Multimodal discourse. The modes and media of contemporary communication. London: Edward Arnold.

Kress, G. (2010). Multimodality. A social semiotic approa porary communication. Oxon: Routledge.

Landow, G. (1995). Hypertext: the convergence of contemporary critical theory and technology. Baltimore: Johns Hopkins University Press.

Ministerio de Educación y Ciencia (2006). Ley Orgánica 2/2006, de 3 de mayo, de Educación. 
Boletín Oficial del Estado, núm. 106.

Nöth, W. (2001). Word and image: Intermedial aspects. Medien Pedagogik. Consultado el 25 de noviembre de 2016 en http://www.medienpaed.com/00-2/noeth1.pdf

Pérez Tornero, J.M., y Sanagustín, P. (2011). De la lectura superficial a la lectura profunda: una escala de las operaciones de lectura en un contexto TIC. Lenguaje y Textos, 34, 17-28.

Prensky, M. (2001). Digital natives, digital immigrants, On the Horizon, 9, 5. Consultado el 25 de noviembre de 2016 en http://www.marcprensky.com/writing/prensky\%20-\%20digital\%20natives,\%20digital\%20immigrants\%20-\%20part1.pdf

Pujolà, J-T., Montmany, B., Palomeque, C., y Suárez, M.M. (2011). The e-portfolio: a pedagogical tool in the middle of the CALL triangle. Simposio presentado en EUROCALL 2011 en Nottingham.

Toffler, A. (1980). The Third Wave. New York: Bantam Books.

Tolsá, J. (2012). Los menores y el mercado de las pantallas: una propuesta de conocimiento integrado. Colección Generaciones Interactivas - Fundación Telefónica. Consultado el 25 de noviembre de 2016 en http://www.generacionesinteractivas.org/upload/libros/Los\%20menores\%20y\%20el\%20mercado\%20de\%20las\%20pantallas.pdf 